\title{
Avaliação de desempenho multicritério como apoio à gestão de empresas: aplicação em uma empresa de serviços
}

\section{Multicriteria performance evaluation as an aid for management of companies: implementation in a service company}

\author{
Sandro César Bortoluzzi ${ }^{1}$ \\ Sandra Rolim Ensslin² \\ Leonardo Ensslin²
}

\begin{abstract}
Resumo: O objetivo deste trabalho consiste em construir um modelo de avaliação de desempenho econômico-financeiro que leve em consideração as particularidades da empresa Seprol Computadores e Sistemas Ltda. e considere indicadores financeiros e não financeiros. Este estudo de caráter exploratório-descritivo, realizado por meio de um estudo de caso, fez uso da abordagem qualitativa, na fase de estruturação do modelo, e quantitativa, na fase de avaliação. A Metodologia Multicritério de Apoio à Decisão Construtivista (MCDA-C) foi o instrumento de intervenção escolhido para desenvolver o modelo, uma vez que é capaz de identificar os objetivos a serem avaliados, mensurar esses objetivos, integrar essas avaliações individuais e gerar ações de aperfeiçoamento para aqueles indicadores que apresentam um desempenho aquém do esperado. A partir do modelo construído, foi possível: (i) identificar os 73 indicadores (30 financeiros e 43 não financeiros) que compõem o modelo a ser utilizado para avaliar o desempenho econômico-financeiro da organização; (ii) identificar as três grandes dimensões que serão avaliadas: gestão financeira (estoque, cobrança interna, rentabilidade); recursos humanos (plano de carreira, qualificação, reconhecimento) e mercado (distribuição, parcerias, marca); (iii) construir escalas ordinais e cardinais para cada indicador do modelo; (iv) avaliar o status quo da organização em 42 pontos, em uma escala de " 0 " a "100", que se configura aquém da expectativa; (v) identificar os 15 indicadores com desempenho comprometedor na organização; e (vi) demonstrar o processo de gerenciamento do desempenho, ilustrado para a dimensão "gestão financeira", ao propor uma ação que, caso seja implantada, virá por elevar sua avaliação para 48 pontos.
\end{abstract}

Palavras-chave: Avaliação de desempenho. Metodologia Multicritério de Apoio à Decisão Construtivista. Medidas financeiras e não financeiras.

\begin{abstract}
The aim of this work is to build a model for the economical and financial performance evaluation that takes the specificities of the company Seprol Computers and Systems Ltd. into consideration and that considers financial and non-financial indicators. This is an exploratory-descriptive study, in which the case study research method was adopted using a qualitative approach during the model structuring phase and quantitative approach in the model evaluation phase. The Multicriteria Decision Aid Constructivist (MCDA-C) was the intervention tool chosen to develop the model since it is able to identify the objectives to be evaluated, measure these objectives, integrate these individual evaluations, and generate improvement actions to the indicators which present a beyond expected performance. Using the model proposed, it was possible: (i) identify the seventy-three indicators (thirty financial and forty-three non-financial elements) that make up the model to be used to evaluate the organization's economical and financial performance; (ii) identify the three great dimensions that will be evaluated: financial management (stock, internal charge, and profitability); human resources (career plan, qualification, and recognition), and market (distribution, partnerships, and brand); (iii) build ordinal and cardinal scales to each indicator of the model; (iv) evaluate the organization's status quo in terms of forty-two aspects in a " 0 " to " 100 " scale, whose performance was considered as below expectation $(v)$ identify the fifteen compromising performance indicators in the organization; and (vi) demonstrate the performance management process for the "financial management" dimension proposing an action which, if implemented, it will increase its evaluation score up to forty-eight.
\end{abstract}

Keywords: Performance evaluation. Multicriteria Decision Aid Constructivist. Financial and non-financial measures.

\footnotetext{
Programa de Pós-graduação em Engenharia de Produção - PPGEP, Universidade Federal de Santa Catarina - UFSC, Professor da Universidade Tecnológica Federal do Paraná - UTFPR, Via do Conhecimento, Km 1, CEP 85503-390, Pato Branco, PR, Brasil, e-mail: sandro@utfpr.edu.br

2 Programa de Pós-graduação em Engenharia de Produção - PPGEP, Programa de Pós-graduação em Contabilidade - PPGC, Universidade Federal de Santa Catarina - UFSC, Campus Universitário, Trindade, CEP 88040-900, Florianópolis, SC, Brasil, e-mail: sensslin@gmail.com; leonardoensslin@gmail.com
}

Recebido em 4/9/2009 — Aceito em 29/6/2011

Suporte financeiro: Nenhum. 


\section{Introdução}

As organizações têm buscado novas ferramentas de gestão para fazer frente a um novo contexto decisório. Esse novo contexto que se apresenta nas últimas décadas traz novos elementos, principalmente intangíveis, que até alguns anos atrás não eram considerados pelas empresas (GUTHRIE, 2001; KAPLAN; NORTON, 2004). Apesar de muitas empresas reconhecerem que esses elementos intangíveis influenciam no desempenho econômicofinanceiro, poucas organizações conseguem de fato gerenciar esses aspectos e até mesmo saber quais são os elementos que impactam no desempenho de sua empresa. Nesse contexto, as pesquisas sobre avaliação de desempenho organizacional têm buscado identificar modelos e discutir aspectos conceituais para atender a essa demanda organizacional (KAPLAN; NORTON, 2000; YEO, 2003; TUOMELA, 2005; JACOBSEN; HOFMANBANG; NORDBY, 2005; GARENGO; BIAZZO; BITITCI, 2005; MERCHANT, 2006; CHENHALL; LANGFIELD-SMITH, 2007; SKRINJAR; BOSILJVUKSIC; INDIHAR-STEMBERGER, 2008; PUNNIYAMOORTHY; MURALI, 2008).

Diversos pesquisadores procuram entender os elementos que devem fazer parte de uma avaliação de desempenho, sendo consenso que se devem considerar as particularidades das organizações. Entende-se por particularidades a cultura, a missão, a visão, os valores, a estratégia e os objetivos de cada organização específica e o que deve ser medido não são somente os aspectos financeiros, mas também os aspectos não financeiros (KAPLAN; NORTON, 2000; YEO, 2003; TUOMELA, 2005; JACOBSEN; HOFMAN-BANG; NORDBY, 2005; GARENGO; BIAZZO; BITITCI, 2005; CHENHALL; LANGBALFIELD-SMITH, 2007; SKRINJAR; BOSILJ-VUKSIC; INDIHAR-STEMBERGER, 2008; PUNNIYAMOORTHY; MURALI, 2008).

Adicionalmente a esses elementos essenciais, a literatura tem abordado a importância de ligar os objetivos estratégicos aos objetivos operacionais, ou seja, ligar os objetivos individuais aos objetivos globais das organizações. (KAPLAN; NORTON, 2000; YEO, 2003; GARENGO; BIAZZO; BITITCI, 2005; PUNNIYAMOORTHY; MURALI, 2008). Além de considerar os aspectos particulares de cada organização e buscar ligar os objetivos estratégicos aos operacionais, parece ser fundamental que todos os níveis organizacionais compreendam quais são seus objetivos. Dessa forma, o sistema de comunicação da empresa deve permitir que todos na organização saibam seus objetivos e consigam visualizar qual a sua contribuição no cumprimento dos objetivos estratégicos, sendo que é importante observar que essa linguagem deve ser clara e holística, caso contrário a informação não irá motivar o alcance dos objetivos, colocando em risco o sucesso da estratégia.

$\mathrm{Na}$ literatura, diversas ferramentas se propõem a avaliar o desempenho organizacional, entre elas, destacam-se a Analytic Hierarchy Process (AHP), o Intellectual Capital Sweden (IC - Rating) e principalmente o Balanced Scorecard (BSC), e algumas variações desse método apresentadas por outros pesquisadores (TUOMELA, 2005; PUNNIYAMOORTHY; MURALI, 2008). Apesar de essas metodologias apresentarem suas vantagens e conseguirem atender a alguns aspectos do novo contexto decisório, as ferramentas apresentam desvantagens em não conseguir atender adequadamente e simultaneamente a alguns requisitos em relação à identificação, mensuração e integração dos critérios, bem como à geração de ações de aperfeiçoamento (IGARASHI et al., 2008).

Nesse contexto, apresenta-se a pergunta que orienta essa pesquisa: quais os indicadores financeiros e não financeiros que devem ser considerados em um modelo de avaliação de desempenho econômicofinanceiro que consiga atender às particularidades da organização? Para responder à pergunta de pesquisa, apresenta-se o objetivo geral do presente trabalho: construir um modelo de avaliação de desempenho econômico-financeiro para a empresa Seprol Computadores e Sistemas Ltda., por meio da Metodologia Multicritério de Apoio à Decisão Construtivista (MCDA-C).

Com a escolha da Metodologia MCDA-C, será possível (i) identificar os indicadores financeiros e não financeiros que respondem pelo desempenho econômico-financeiro da empresa; (ii) construir escalas ordinais e cardinais para os indicadores identificados; (iii) traçar o perfil de desempenho e avaliar o desempenho local e global; e (iv) identificar os indicadores que necessitem de ações de aperfeiçoamento.

A metodologia Multicritério de Apoio à Decisão Construtivista (MCDA-C) foi escolhida como instrumento de intervenção para a presente pesquisa, por se diferenciar em relação às metodologias tradicionais de MCDA, principalmente em relação à estruturação do contexto decisório (ENSSLIN et al., 2010).

A metodologia MCDA-C tem sua consolidação como instrumento científico de gestão a partir da década de 1980 com os trabalhos de Roy (1996) e Landry (1995) ao definir os limites da objetividade para os processos de apoio à decisão, de Skinner (1986) e Keeney (1992) ao reconhecer que os atributos (objetivos, critérios) são específicos ao 
decisor em cada contexto, de Bana e Costa (1993) ao explicitar as convicções da MCDA (ENSSLIN et al., 2010).

A MCDA-C pode ser entendida como uma ramificação da MCDA tradicional para apoiar os decisores em contextos complexos, conflituosos e incertos. Complexos por envolverem múltiplas variáveis qualitativas e quantitativas, parcialmente ou não explicitadas. Conflituosos por envolverem múltiplos atores com interesses não necessariamente alinhados e/ou com preocupações distintas do decisor que não tem interesse de confrontá-los. Incertos por requererem o conhecimento de informações qualitativas e quantitativas que os decisores reconhecem não saber quais são, mas que desejam desenvolver este conhecimento para poder tomar decisões conscientes e segundos seus valores e preferências (ENSSLIN et al., 2010).

A problemática das metodologias MCDA tradicionais é a escolha da solução ótima dentre alternativas pré-existentes. Em contraste, a metodologia MCDA-C busca desenvolver no decisor um corpo coerente de conhecimentos capaz de lhe permitir compreender as consequências de suas decisões nos aspectos que o próprio decisor julga importante (ENSSLIN et al., 2010).

Em síntese, a preocupação mais relevante para os pesquisadores de MCDA-C é a construção do conhecimento no decisor, ou seja, assume uma lógica de pesquisa construtivista, já as metodologias da MCDA tradicionais assumem uma lógica de pesquisa racionalista. Conhecimento aprofundado sobre as diferenças entre a metodologia MCDA-C e as metodologias MCDA tradicionais podem ser encontras em Ensslin et al., (2010).

O trabalho se justifica em três eixos: (i) contribuição teórica, pois o estudo proporciona uma revisão teórica sobre o tema avaliação de desempenho organizacional (ADO) e realiza uma análise crítica da literatura; (ii) contribuição prática ao tema de ADO econômico-financeiro por apresentar um processo estruturado de ADO; e (ii) contribuição prática à metodologia MCDA-C, com aplicação da metodologia em um estudo de caso. Em função da contribuição teórica e prática, o trabalho se torna relevante, pois pretende contribuir com a ADO com o uso de uma ferramenta que permite uma visão diferenciada em relação às ferramentas encontradas na literatura.

O presente artigo está organizado em seis seções. Além desta seção introdutória, o artigo apresenta, na seção 2, o referencial teórico. A seção 3 apresenta a metodologia da pesquisa. Na seção 4, apresentam-se os resultados da pesquisa. Na seção 5, apresentam-se as considerações finais e, por fim, as referências utilizadas neste trabalho.

\section{Referencial teórico}

Nesta seção, buscou-se analisar aspectos relacionados: (i) ao conceito e elementos da avaliação de desempenho organizacional; e (ii) à análise das ferramentas encontradas na literatura.

\subsection{Conceitos e elementos da avaliação de desempenho organizacional (ADO)}

A construção de um sistema de ADO deve considerar elementos fundamentais, tais como: missão, visão, cultura e estratégia organizacional, objetivos de longo prazo e curto prazo e comunicação (feedback) (KAPLAN; NORTON, 2000; YEO, 2003; TUOMELA, 2005; JACOBSEN; HOFMANBANG; NORDBY, 2005; GARENGO; BIAZZO; BITITCI, 2005; MERCHANT, 2006; CHENHALL; LANGFIELD-SMITH, 2007; SKRINJAR; BOSILJVUKSIC; INDIHAR-STEMBERGER, 2008; PUNNIYAMOORTHY; MURALI, 2008).

Percebe-se a preocupação com os aspectos considerados estratégicos, que são diretrizes demandadas pela alta administração, com os aspectos considerados operacionais, que fazem parte do dia a dia dos colaboradores das organizações. Essa ligação entre o que é estratégico com o que é operacional parece ser fundamental em um sistema de ADO. Possibilitar ao gestor uma clara linha de visão, que torne possível alinhar os objetivos individuais com os objetivos globais da organização, parece ser o dilema a ser resolvido (KAPLAN; NORTON, 2000; YEO, 2003; PUNNIYAMOORTHY; MURALI, 2008).

Além de levar em consideração os aspectos estratégicos e conseguir traduzir a estratégia em objetivos operacionais, é necessário que um processo de comunicação consiga fazer com que todos da organização saibam o que realmente se está perseguindo, caso contrário pode acontecer que uma excelente estratégia não tenha sucesso, por falta de um sistema de feedback adequado. (KAPLAN; NORTON, 2000; TUOMELA, 2005).

Os elementos que, segundo a literatura, devem fazer parte do processo de avaliação de desempenho podem ser visualizados no Quadro 1. Adicionalmente aos elementos estratégicos e operacionais, e à premissa de levar em consideração as particularidades de cada organização, percebe-se a preocupação em considerar todos os stakeholders, sejam eles internos ou externos. A literatura aborda também que os sistemas de ADO devem levar em consideração uma visão holística da organização (KAPLAN; NORTON, 2000), ou seja, não 
Quadro 1. Elementos essenciais aos sistemas de avaliação de desempenho.

\begin{tabular}{|c|c|}
\hline Elementos & Autor(es) \\
\hline $\begin{array}{l}\text {-Alinhamento estratégico } \\
\text { (relação causa e efeito) }\end{array}$ & $\begin{array}{l}\text { Kaplan e Norton (2000), Yeo (2003), Garengo, Biazzo e } \\
\text { Bititci (2005), Punniyamoorthy e Murali (2008) }\end{array}$ \\
\hline -Linguagem clara e holística dos objetivos & Kaplan e Norton (2000), Garengo, Biazzo e Bititci (2005) \\
\hline $\begin{array}{l}\text { - Consideração de todos os processos e níveis } \\
\text { organizacionais }\end{array}$ & Yeo $(2003)$ \\
\hline $\begin{array}{l}\text {-Visão estratégica da organização } \\
\text { (perspectiva futura) }\end{array}$ & $\begin{array}{c}\text { Kaplan e Norton (2000), Tuomela (2005), Jacobsen, } \\
\text { Hofman-bang e Nordby (2005), Garengo, Biazzo e Bititci (2005), } \\
\text { Punniyamoorthy e Murali (2008), Han e Han (2004) }\end{array}$ \\
\hline - Sistema de feedback (comunicação) & Tuomela (2005) \\
\hline - Missão da organização & $\begin{array}{c}\text { Jacobsen, Hofman-bang e Nordby (2005), } \\
\text { Punniyamoorthy e Murali (2008) }\end{array}$ \\
\hline - Objetivos organizacionais & $\begin{array}{c}\text { Skrinjar; Bosilj-vuksic; Indihar-stemberger, (2008), } \\
\text { Bortoluzzi et al. (2010) }\end{array}$ \\
\hline $\begin{array}{l}\text {-Envolvimento de todos os stakeholders } \\
\text { (internos e externos à organização) }\end{array}$ & $\begin{array}{c}\text { Yeo (2003), Han e Han (2004), Jacobsen, Hofman-bang e } \\
\text { Nordby (2005), Garengo, Biazzo e Bititci (2005), } \\
\text { Skrinjar, Bosilj-vuksic e Indihar-stemberger (2008) }\end{array}$ \\
\hline
\end{tabular}

Fonte: elaborado pelos autores.

deve ser um sistema isolado, mas sim integrar todos os processos e níveis organizacionais (YEO, 2003).

Nesse contexto, em que se salientam os elementos que devem fazer parte de uma avaliação de desempenho, cumpre esclarecer a afiliação teórica do trabalho, no que tange o conceito de avaliação de desempenho organizacional. Os autores afiliam-se à definição de ADO formulada por Igarashi et al. (2008, p.119). Segundo a ótica desses pesquisadores, uma avaliação válida e legítima deve investigar:

[...] o que vai ser avaliado - ou seja, conhecer o objeto da avaliação, incluindo aqui a sua identidade, a cultura sobre a qual esta identidade é construída, as instâncias que respondem pelo objeto a ser avaliado, resultando nos objetivos a serem perseguidos; (ii) como proceder à avaliação - ou seja, identificar como cada objetivo será avaliado e quanto cada objetivo contribui para a avaliação do todo, possibilitando a identificação do perfil de desempenho do objeto avaliado; (iii) como conduzir ao gerenciamento interno - com base na análise das fragilidades e potencialidades identificadas para sugerir ações de aperfeiçoamento - promovendo a alavancagem do desempenho institucional.

A partir desta definição de avaliação de desempenho, observa-se que esta se aplica apenas para contextos em que podem ser atendidos os paradigmas abordados no Quadro 2.

A metodologia MCDA-C rege-se por estes paradigmas.

Observa-se que a afiliação teórica adotada contempla os elementos citados na literatura como importantes na construção de sistemas de ADO.
Na ótica desses pesquisadores, a construção de um sistema de ADO deve considerar as particularidades de cada organização, pois é bastante incomum encontrar duas empresas que sejam iguais, por isso, deve-se considerar a missão, visão e estratégia de cada empresa (JACOBSEN; HOFMAN-BANG; NORDBY, 2005). Nesse sentido o conceito de ADO apresentado destaca que se deve conhecer o que vai ser avaliado, pois cada empresa tem sua cultura, missão, visão e estratégia, e essas particularidades devem ser atendidas em um sistema de ADO.

O conceito de ADO salienta ainda a importância de identificar como cada critério será avaliado, e quanto cada critério contribui para a avaliação global de desempenho, possibilitando a identificação do perfil de desempenho. Quanto a esse aspecto, percebe-se a preocupação dos pesquisadores em relação à linguagem clara e visão holística dos objetivos, que, segundo a literatura, são elementos essenciais dos sistemas de ADO (KAPLAN; NORTON, 2000). Por fim, o conceito de avaliação de desempenho apresentado destaca o uso das informações geradas pelos sistemas de avaliação de desempenho, ou seja, é fundamental o uso das informações geradas para apoiar o gestor no gerenciamento das potencialidades e fragilidades da organização, buscando alavancar o desempenho institucional.

\subsection{Análise das ferramentas utilizadas nos artigos estudados}

$\mathrm{Na}$ literatura estudada, a ferramenta mais utilizada foi o Balanced Scorecard (BSC), em sua versão original ou com algumas adaptações (feitas por outros pesquisadores). Aparecem também a 
Quadro 2. Paradigmas da metodologia MCDA-C.

\begin{tabular}{|lr|}
\hline \multicolumn{1}{|c|}{ Paradigmas do apoio à decisão (MCDA-C) } & Descrição do paradigma \\
\hline P1 = Singularidade, identidade & Os valores e preferências do decisor \\
P2 = Conhecimentos limitados & $\begin{array}{c}\text { A necessidade do decisor em melhorar seu } \\
\text { entendimento das consequências da decisão }\end{array}$ \\
P3 = Entidade social & $\begin{array}{r}\text { Oportunizar aos stakeholders com interesses na decisão a } \\
\text { submeterem e defenderem seus interesses na decisão }\end{array}$ \\
P4 = Recursividade da aprendizagem participativa & A dinâmica recursiva do processo de aprendizagem \\
P5 = Princípios da mensuração & $\begin{array}{c}\text { As propriedades das escalas ordinais, } \\
\text { de intervalo, e de razão }\end{array}$ \\
P6 = Legitimidade e validação & $\begin{array}{c}\text { A transparência da participação, o reconhecimento da } \\
\text { utilidade do conhecimento gerado e a cientificidade do } \\
\text { processo de construção do conhecimento utilizado. }\end{array}$ \\
\hline
\end{tabular}

Fonte: adaptado de Lacerda, Ensslin e Ensslin (2011a).

Quadro 3. Análise das ferramentas encontradas nos artigos estudados.

\begin{tabular}{|c|c|c|c|c|c|}
\hline Ferramenta & Autor & Identifica & Mensura & Integra & Gerencia \\
\hline $\begin{array}{l}3 K \text { Scorecard } \\
\text { (variante do } \\
\text { BSC) }\end{array}$ & $\begin{array}{l}\text { Tuomela (2005), } \\
\text { baseado no } \\
\text { BSC de Kaplan; } \\
\text { Norton (1992, } \\
\text { 1996) }\end{array}$ & $\begin{array}{l}\text { - Sim. Entrevista } \\
\text { e consulta de } \\
\text { documentos internos. } \\
\text { No entanto, o } \\
\text { processo poderia ser } \\
\text { mais completo. }\end{array}$ & $\begin{array}{c}\text { - Sim. No } \\
\text { entanto, a } \\
\text { mensuração é } \\
\text { apenas ordinal. }\end{array}$ & $\begin{array}{c}\text { - Não. A } \\
\text { ferramenta } \\
\text { não se propõe } \\
\text { a integrar os } \\
\text { critérios. }\end{array}$ & $\begin{array}{c}\text { - Sim. Apresenta } \\
\text { os resultados aos } \\
\text { gestores. No entanto, } \\
\text { não permite identificar } \\
\text { o impacto de uma ação } \\
\text { no desempenho global. }\end{array}$ \\
\hline $\begin{array}{l}\text { Balanced } \\
\text { Scorecard } \\
(\mathrm{BSC})\end{array}$ & $\begin{array}{c}\text { Kaplan; Norton } \\
(1992,1996)\end{array}$ & $\begin{array}{l}\text { - Sim. Usa técnica } \\
\text { brainstorming. No } \\
\text { entanto o processo } \\
\text { poderia ser mais } \\
\text { completo. }\end{array}$ & $\begin{array}{l}\text { - Sim. Mensura } \\
\text { os critérios de } \\
\text { forma ordinal. }\end{array}$ & $\begin{array}{c}\text { - Não. A } \\
\text { avaliação é } \\
\text { pontual em } \\
\text { cada critério. }\end{array}$ & $\begin{array}{c}\text { - Sim. O } \\
\text { gerenciamento } \\
\text { acontece nos } \\
\text { indicadores } \\
\text { comprometedores. No } \\
\text { entanto, a ferramenta } \\
\text { poderia disponibilizar } \\
\text { melhores informações. }\end{array}$ \\
\hline $\begin{array}{l}\text { Score card } \\
\text { para o } \\
\text { Balanced } \\
\text { Scorecard } \\
\text { (BSC) }\end{array}$ & $\begin{array}{l}\text { Punniyamoorthy; } \\
\text { Murali (2008) } \\
\text { baseado no } \\
\text { BSC de Kaplan; } \\
\text { Norton (1992, } \\
\text { 1996) }\end{array}$ & $\begin{array}{c}\text { - Sim. Entrevistas e } \\
\text { brainstorming. No } \\
\text { entanto, percebe- } \\
\text { se que o processo } \\
\text { poderia ser mais } \\
\text { completo. }\end{array}$ & $\begin{array}{l}\text { - Sim. } \\
\text { Ferramenta } \\
\text { utiliza escalas } \\
\text { ordinais. }\end{array}$ & $\begin{array}{c}\text { - Sim. } \\
\text { Utiliza-se de } \\
\text { um processo } \\
\text { de agregação. }\end{array}$ & $\begin{array}{c}\text { - Sim, o gerenciamento } \\
\text { acontece nos } \\
\text { indicadores } \\
\text { comprometedores. }\end{array}$ \\
\hline $\begin{array}{l}\text { Analytic } \\
\text { Hierarchy } \\
\text { Process } \\
\text { (AHP) }\end{array}$ & Saaty(1988) & $\begin{array}{c}\text { - Não. Parte de uma } \\
\text { estrutura prévia } \\
\text { do que se pretende } \\
\text { avaliar. }\end{array}$ & $\begin{array}{l}\text { - Sim. Faz a } \\
\text { mensuração de } \\
\text { forma ordinal. }\end{array}$ & $\begin{array}{l}\text { - Não, pois } \\
\text { não tem um } \\
\text { processo de } \\
\text { agregação. }\end{array}$ & $\begin{array}{l}\text { - Não. Apresenta uma } \\
\text { relação de alternativas } \\
\text { hierarquizadas para } \\
\text { que uma ou mais seja } \\
\text { escolhida. }\end{array}$ \\
\hline IC Rating & $\begin{array}{c}\text { Intellectual } \\
\text { Capital Sweden }\end{array}$ & $\begin{array}{c}\text { - Não. A ferramenta } \\
\text { utiliza critérios } \\
\text { padronizados }\end{array}$ & $\begin{array}{c}\text { - Sim. A } \\
\text { mensuração } \\
\text { por meio de } \\
\text { classificação }\end{array}$ & $\begin{array}{c}\text { - Não. A } \\
\text { ferramenta } \\
\text { integra }\end{array}$ & $\begin{array}{l}\text { - Sim. Tem o objetivo } \\
\text { de gerenciar os } \\
\text { aspectos considerados } \\
\text { ineficientes }\end{array}$ \\
\hline
\end{tabular}


ferramenta Analytic Hierarchy Process (AHP) e a ferramenta IC Rating, que tem como foco o capital intelectual. No Quadro 3, busca-se realizar uma análise das ferramentas encontradas no que diz respeito aos quatro elementos do conceito de $\mathrm{AD}$ adotado.

$\mathrm{Na}$ análise do Quadro 3, percebe-se que, em relação à afiliação teórica sobre avaliação de desempenho adotada neste trabalho e que caracteriza as convicções dos autores deste estudo, as ferramentas encontradas apresentam algumas limitações. No que diz respeito a identificar os critérios que serão avaliados, as ferramentas AHP e IC Rating não permitem a identificação dos critérios, ou seja, já partem de uma estrutura prévia de indicadores. O Balanced Scorecard e as outras duas ferramentas, que são uma variação do BSC (3K Scorecard e Score card para o BSC), possibilitam a identificação dos critérios; entretanto, não são processos estruturados, ou seja, a identificação desses critérios irá depender das aptidões do facilitador. Outro aspecto que pode ser destacado sobre essas últimas ferramentas é que suas estruturas já partem de algumas dimensões previamente estipuladas. Por exemplo, parte-se das perspectivas financeira, clientes, processos internos e aprendizado e crescimento, o que pode levar o gestor ao entendimento de que existem apenas essas dimensões e de que todos os aspectos que possam ser avaliados devem ser encaixados em cada uma dessas perspectivas. Consequentemente, essa limitação pode restringir uma visão holística da organização.

No que diz respeito à mensuração dos critérios, percebe-se que todas as ferramentas encontradas permitem a mensuração. Todavia, a forma de mensuração é ordinal, isto é, não se leva em consideração a diferença de atratividade entre os níveis de desempenho em cada escala (indicador). Ou seja, as metodologias entendem que, em qualquer indicador, passar de um nível de desempenho para outro é percebido igualmente pelos gestores.

Em relação à integração dos indicadores, praticamente a grande maioria das ferramentas não apresenta um processo de agregação aditiva, para se ter uma avaliação global de desempenho. A ferramenta Score card para o BSC apresenta um processo para realizar a integração, sendo que destaca a importância dessa etapa para a avaliação de desempenho.

As ferramentas que apresentam o processo de gerenciamento indicam que deve haver o aperfeiçoamento dos indicadores que apresentarem desempenho abaixo do esperado, mas não estruturam a forma como esse gerenciamento deve ser conduzido.

A Metodologia Multicritério de Apoio à Decisão Construtivista (MCDA-C), escolhida para a presente pesquisa, consegue atender aos aspectos de identificação, mensuração, integração dos critérios e geração de ações de aperfeiçoamento, conforme apresentado no Quadro 4.

A identificação dos critérios relevantes para o decisor é realizado pela metodologia MCDA-C por meio de um processo, que tem como principal objetivo gerar conhecimento no decisor sobre quais aspectos são importantes no contexto e que necessitam ser considerados em um modelo de avaliação de desempenho.

O processo de identificação na metodologia MCDA-C começa com o entendimento do contexto, identificando em qual ambiente é realizada a gestão e com a definição dos atores que participam direta ou indiretamente ao processo de gestão. Na sequência, para identificar os critérios relevantes, busca-se criar entendimento no decisor por meio da identificação dos elementos primários de avaliação (EPAs), transformação desses elementos primários em conceitos orientados à ação, agrupamentos dos conceitos em áreas de preocupação, identificação da família de pontos de vista fundamentais, operacionalização das famílias de pontos de vista fundamentais por meios de pontos de vista elementares e descritores, identificação pelo decisor dos níveis de referência, incorporação do juízo de valor preferencial entre os níveis dos descritores para sua transformação em escala de intervalo (cardinal), construção, integração das escalas cardinais construídas por meio de taxas de compensação determinadas a partir dos níveis de referência adotado, explicitação do perfil de desempenho (gráfico) das alternativas existentes, explicitação da equação geral que representa o modelo matemático para calcular numericamente a performance da alternativa. A metodologia MCDA-C ainda propicia oportunidades para buscar aperfeiçoamento das alternativas valendo-se do conhecimento construído no descritor. (BORTOLUZZI; ENSSLIN; ENSSLIN, 2010a; LACERDA; ENSSLIN; ENSSLIN, 2011b).

A mensuração é realizada pela metodologia MCDA-C por meio de escalas que atendem à teoria da mensuração e às propriedades de operacionalização das escalas, conforme preconizado nos trabalhos de Barzilai (1997); Roberts (1979); Ensslin, Montibeller e Noronha (2001). Na metodologia MCDA-C, as escalas são construídas em vários momentos: (i) mapas cognitivos para associar as preocupações abstratas do decisor às propriedades físicas do contexto; (ii) construção de descritor (escala ordinal) representando a cadeia de relações meios-fins do mapa cognitivo; (iii) identificação dos níveis de referência (âncoras) que o decisor estabelece para estratificar o espaço amostral nos subconjuntos desempenho comprometedor, desempenho de mercado e desempenho em nível de excelência; (iv) função de valor (escala cardinal de intervalo) construída a 
Quadro 4. Processo desenvolvido pela metodologia MCDA-C.

\begin{tabular}{|lcccc|}
\hline \multicolumn{1}{|c}{ Ferramenta } & \multicolumn{1}{c}{ Identifica } & Mensura & Integra & Gerencia \\
\hline Metodologia & - Sim. Por meio de: (i) & - Sim. Os objetivos & - Sim. A & - Sim. Apresenta \\
Multicritério & entendimento do contexto; & são mensurados & metodologia & processo para \\
de Apoio & (ii) identificação dos & primeiramente & MCDA-C & identificar os pontos \\
à Decisão & atores; (iii) elementos & ordinalmente na & permite integrar & fortes e fracos do \\
(MCDA-C) & primários de avaliação; & fase de estruturação & os descritores & desempenho que \\
& (iv) conceitos orientados à & e, posteriormente, & para se ter uma & podem ser visualizados \\
& ação; (v) agrupamento em & cardinalmente pela & avaliação global & graficamente e \\
& áreas de preocupação; (vi) & construção de uma & de desempenho. & numente. \\
& identificação da família de & função de valor que & & Adicionalmente \\
& pontos de vista fundamentais; & informará a diferença & & permite identificar os \\
& (vii) operacionalização dos & de atratividade para o & & no desempenho global. \\
& pontos de vista fundamentais & decisor entre um nível & & \\
& por meio dos pontos de vista & e outro do descritor. & & \\
& elementares e descritores; & & & \\
& (viii) níveis de referência. & & & \\
\end{tabular}

Fonte: Bortoluzzi, Ensslin e Ensslin, (2010a).

partir da incorporação de dados sobre a diferença de atratividade entre os níveis fornecidos pelo decisor (BORTOLUZZI; ENSSLIN; ENSSLIN, 2010b).

A metodologia MCDA-C consegue realizar a integração dos indicadores para se ter uma avaliação global de desempenho. Os aspectos que permitem a integração dos descritores são: (i) ter as escalas cardinais com seus níveis de referência explicitados; (ii) o reconhecimento que as taxas correspondem ao acréscimo de valor propiciado pelo mudança de desempenho do nível de referência "neutro" para o nível de referência "bom"; (iii) ser possível associar a cada critério uma ação que represente a contribuição provocada pelo acréscimo de desempenho de passar do nível de referência "neutro" para o nível de referência "bom"; (iv) ser possível o decisor explicitar a ordenação das alternativas anteriores; (v) ser possível o decisor explicitar a diferença de atratividade entre as alternativas. Uma vez atendidas essas condições é sempre possível identificar as taxas que atendem a todos os juízos preferenciais do decisor (BORTOLUZZI; ENSSLIN; ENSSLIN, 2010a; BORTOLUZZI; ENSSLIN; ENSSLIN, 2011).

Em relação à geração de ações de aperfeiçoamento, a metodologia MCDA-C apresenta um processo que permite identificar os pontos fortes e fracos da situação atual em cada descritor e por meio do perfil de impacto da situação atual. Estes aspectos críticos poderão ser visualizados graficamente e numericamente. Adicionalmente, o processo permite identificar o impacto de uma ação ou estratégia no desempenho global. Isso possibilita conhecer as consequências de cada alternativa naqueles aspectos julgados pelo decisor como necessários e suficientes para avaliar o contexto. Este conhecimento na metodologia MCDA-C é apresentado em forma gráfica e numérica.

\section{Metodologia da pesquisa}

Esta seção tem o objetivo de apresentar (i) o enquadramento metodológico da pesquisa; (ii) os procedimentos para revisão da literatura; e (iii) os procedimentos para construção do modelo.

\subsection{Enquadramento metodológico}

A presente pesquisa possui caráter exploratóriodescritivo. Exploratório, pois busca aprofundar os aspectos relacionados ao desempenho econômicofinanceiro da empresa Seprol Computadores Ltda. (GIL, 1999); descritivo porque, na revisão da literatura, faz uma análise crítica do que já foi publicado sobre avaliação de desempenho organizacional e descreve essas características (GIL, 1999), comparando-as ou confrontando-as com o modelo desenvolvido.

Trata-se de um estudo de caso (estudo prático), pois o modelo foi construído para uma empresa específica e com o objetivo de avaliar o desempenho econômico-financeiro dessa empresa na percepção de seus gestores; o que permitiu interagir com os decisores e preservar as características da empresa em funcionamento (YIN, 2003). Sendo assim, a pesquisa é aplicada, pois busca construir um modelo para uma empresa específica (GIL, 1999), levando em consideração as percepções dos decisores da empresa. O trabalho também tenciona gerar conhecimento nos decisores, e o resultado desse conhecimento será representado por um modelo de avaliação de desempenho econômico-financeiro.

Em relação à coleta de dados, a pesquisa fez uso de dados primários, que são os dados colhidos diretamente em campo por meio de entrevistas (RICHARDSON, 1999). No que se refere à abordagem do problema, a pesquisa caracteriza-se como qualitativa, na fase 
de estruturação do modelo, quando da reflexão para identificação e representação dos indicadores que serão utilizados para avaliar o desempenho econômico-financeiro da Seprol, bem como na construção das escalas ordinais (indicadores) e na fase de recomendação, quando do processo de geração de ações de aperfeiçoamento; e quantitativa na fase de avaliação quando da tradução do modelo qualitativo em quantitativo e quando da utilização do método de agregação aditiva. $\mathrm{O}$ instrumento de intervenção escolhido para construção do modelo foi a Metodologia Multicritério de Apoio à Decisão Construtivista (MCDA-C). A MCDA-C, tendo por base as convicções e valores dos envolvidos no processo, busca estruturar o contexto decisional com vistas a desenvolver modelos (a partir da identificação, mensuração, integração e geração de ações de aperfeiçoamento para aqueles indicadores que apresentam um desempenho aquém do esperado), nos quais os decisores possam basear suas decisões a partir do que eles acreditam ser o mais adequado (ROY, 1993; CARPES; ENSSLIN; ENSSLIN, 2006). Neste ponto verifica-se a aderência da filosofia da metodologia MCDA-C à afiliação teórica de ADO dessa pesquisa.

Em relação aos procedimentos técnicos, a pesquisa é bibliográfica, na medida em que se utiliza de um processo sistematizado para realizar o levantamento do que já foi pesquisado sobre o tema em estudo (GIL, 1999).

\subsection{Procedimentos para revisão da literatura}

A revisão da literatura ocorreu nas bases de dados constantes no portal da CAPES (Coordenação de Aperfeiçoamento do Pessoal do Ensino Superior), disponíveis na seguinte página da internet: http://www.periodicos.capes.gov.br. O processo desenvolvido para a revisão da literatura foi baseado na pesquisa de Tasca et al. (2010). A etapa inicial consistiu em identificar as áreas que fariam parte da pesquisa, sendo selecionadas as seguintes: multidisciplinar, administração, negócios, contabilidade, ciências sociais e engenharia de produção. Com a definição das áreas, buscou-se na base de dados do portal de periódicos da CAPES as bases que continham em sua descrição pelo menos uma das áreas.

A etapa seguinte consistiu em selecionar os artigos. Primeiramente, identificaram-se as palavras-chave prioritárias: financial; management; organization. Na sequência, as palavras-chave complementares: performance; measures; measurement; evaluation; ratios; non-financial. Os artigos selecionados continham no título, e/ou palavras-chave, e/ou resumo todas as palavras-chave prioritárias e uma das complementares. Nessa etapa, foram encontrados 6.411 artigos para o período de 2000 a $2008 . \mathrm{Na}$ sequência, buscou-se a exclusão das bases de dados com conteúdo nulo ou minoritário. Nesse momento, selecionaram-se as sete bases de dados que representavam $97 \%$ dos artigos encontrados, resultando em 6.197 artigos.

Em seguida, buscou-se excluir as bases de dados que não continham artigos que não foram avaliados por referees. Nessa etapa, foram excluídas duas bases de dados: Wilson e Gale. Após essa etapa, restaram 4.723 artigos. A etapa seguinte consistiu em transferir os 4.723 artigos para um software de gerenciamento de referências bibliográficas, com o objetivo de realizar as demais etapas do processo em uma única base de dados. Após a exportação dos artigos, procedeu-se à exclusão dos artigos duplicados, utilizando o comando do próprio software. Com isso, a amostra reduziu para 3.406 artigos.

Na sequência, realizou-se a exclusão dos artigos relacionados aos periódicos que não tinham como foco publicações nas áreas de interesse da pesquisa, delimitando a amostra a 1.020 artigos. Em seguida, realizou-se a leitura dos resumos para selecionar apenas os artigos que focalizavam a ADO, desta análise restaram 137 artigos.

Na sequência, o critério utilizado baseou-se no reconhecimento do meio científico, por meio da quantidade de vezes que o artigo foi citado. Foram identificados 94 artigos candidatos à aceitação que foram citados pelo menos uma vez e 43 artigos candidatos à exclusão que não tiveram nenhuma citação.

A etapa seguinte consistiu no reexame dos 43 artigos candidatos à exclusão, por meio de uma leitura dinâmica de seus resumos, para assegurar que não existiam artigos que eram relevantes para a pesquisa. Após a leitura desses resumos, foram incorporados ao corpus desta pesquisa cinco artigos que eram candidatos à exclusão. Portanto, dos 43 artigos candidatos à exclusão, foram excluídos 38 artigos e incorporados cinco artigos aos 94 candidatos à aceitação, totalizando 99 artigos para a análise da próxima etapa.

A última etapa incluiu a leitura detalhada dos 99 artigos, com o objetivo de manter os mais alinhados ao tema investigado (avaliação de desempenho organizacional econômico-financeiro) e que fossem ao encontro dos objetivos da pesquisa. Após essa etapa, restaram 14 artigos totalmente alinhados com a pesquisa. Desses 14 artigos, 12 foram utilizados, pois dois artigos não estavam disponíveis na íntegra. 


\subsection{Procedimentos para construção do modelo}

A fase de estruturação inicia-se pela identificação do contexto decisório em que são apresentados os atores, ou seja, aqueles que participam, direta ou indiretamente, do processo da construção do modelo. Os atores desse processo são: o decisor; o facilitador; os intervenientes e os agidos. Na sequência deve-se definir o rótulo para o problema. O rótulo consiste em elaborar o enunciado do problema e deve conter o foco principal do trabalho, indicando o propósito a ser atingido (ENSSLIN; MONTIBELLER; NORONHA, 2001).

Após essas etapas iniciais, identificam-se os Elementos Primários de Avaliação (EPAs) que são as preocupações manifestadas pelos decisores, quando questionados sobre o problema (ENSSLIN; MONTIBELLER; NORONHA, 2001). Os EPAs são transformados em conceitos, os quais identificam dois pólos - o pólo presente (pretendido) e o pólo oposto (mínimo aceitável pelo decisor). Os conceitos têm o objetivo de gerar uma melhor compreensão das preocupações, deixando claras as fronteiras entre o pretendido e o mínimo aceitável (ENSSLIN; LIMA, 2008). A partir da formulação dos conceitos, estes são agrupados em áreas de afinidades, ou clusters (EDEN, 1988) sendo, então, estruturados hierarquicamente com base em suas relações de influência. Essa estrutura hierárquica é denominada, na metodologia MCDA-C, Árvore de Pontos de Vista (BANA E COSTA; SILVA, 1994) ou estrutura hierárquica de valores (KEENEY, 1992). Construída a árvore de pontos de vista, a próxima etapa da fase de estruturação do modelo consiste na construção dos descritores (escalas ordinais), que vão permitir a mensuração e a avaliação do desempenho local da organização em cada objetivo.

A Fase de Avaliação propõe-se, em primeiro lugar, a determinar escalas cardinais locais, por meio da construção das funções de valor para os descritores (escalas ordinais). Neste trabalho, esse processo foi realizado com o auxílio do software Macbeth-scores (BANA E COSTA; VANSNICK, 1997). Para tanto, são definidos níveis de referência para cada descritor (BANA E COSTA; SILVA, 1994), também conhecidos como níveisâncora (Bom e Neutro). Esses níveis informam as faixas limítrofes, no interior das quais os níveis de impacto são considerados como em nível de mercado - entre os níveis Bom e Neutro; como em nível comprometedor - abaixo do Neutro; e, como em nível de excelência - acima do Bom. Terminada a ancoragem, é importante identificar a diferença de atratividade entre os níveis da escala (perda de atratividade percebida na passagem de um nível do descritor para outro determinados anteriormente). Para tanto, utiliza-se o método do julgamento semântico, por meio de comparações par-a-par e utilizando-se o software Macbeth-scores (BANA E COSTA; STEWART; VANSNICK, 1995).

A etapa seguinte da fase de Avaliação consiste na identificação das taxas de substituição que informam a importância relativa de cada elemento para o modelo como um todo. Após a obtenção das taxas de substituição de cada elemento (critério), pode-se transformar o valor da avaliação de cada critério em valores de uma avaliação global. Com as taxas de substituição, o modelo de avaliação multicritério para a ADO da organização está concluído. Uma vez que também se objetiva conhecer o desempenho global da organização, cabe, agora, agregar as avaliações locais, por meio da seguinte equação matemática (Equação 1) de agregação aditiva:

$$
V(a)=\sum w_{i} X \underset{\substack{n \\ v_{i=1}}}{n}(a)
$$

em que:

V (a) = valor do Desempenho econômicofinanceiro Global;

$\mathrm{v}_{1}(\mathrm{a}), \mathrm{v}_{2}(\mathrm{a}), \ldots \mathrm{v}_{\mathrm{n}}(\mathrm{a})=$ valor parcial do desempenho econômico-financeiro nos critérios 1, 2, n;

$\mathrm{w}_{1}, \mathrm{w}_{2}, \ldots \mathrm{w}_{\mathrm{n}}=$ taxas de substituição nos critérios $1,2, \ldots \mathrm{n}$;

$\mathrm{n}=\mathrm{n}^{\mathrm{o}}$ de critérios do modelo.

Justifica-se o uso da agregação aditiva no presente estudo em função da oportunidade de conhecer o desempenho global. A agregação aditiva dos critérios permite identificar o impacto de uma ação ou estratégia no desempenho global da organização. Esse aspecto é importante à medida que o decisor precisa identificar qual o impacto de uma ação operacional no desempenho tático e/ou estratégico da organização, principalmente em empresas onde os recursos são limitados e o gestor precisa identificar a relação custo vs. benefício da escolha de determinada ação ou estratégia. O custo de uma ação ou estratégia é relativamente fácil de identificar, no entanto, o decisor normalmente tem dificuldade de identificar o benefício de uma ação no desempenho tático e estratégico. Desta forma, a agregação aditiva proporcionada pela metodologia MCDA-C permite esse conhecimento para apoiar o gestor na tomada de decisão (BORTOLUZZI; ENSSLIN; ENSSLIN, 2010a, 2011)

A agregação aditiva é realizada na metodologia MCDA-C pela transformação das escalas ordinais em escalas cardinais e também pela 
identificação das taxas de compensação. O processo de operacionalização das escalas ordinais em escalas cardinais e a identificação das taxas de compensação são esclarecidos nesta seção quando aborda a fase de avaliação da construção do modelo.

A próxima seção objetiva demonstrar a construção do modelo de avaliação de desempenho econômicofinanceiro da empresa Seprol Computadores e Sistemas Ltda.

\section{Resultados}

Nesta seção são apresentados os resultados da pesquisa realizada na empresa Seprol Computadores e Sistemas Ltda. Salienta-se que a pesquisa teve por objetivo construir um modelo de avaliação de desempenho econômico-financeiro, por meio da Metodologia Multicritério de Apoio à Decisão Construtivista (MCDA-C), sendo que os procedimentos para construção do modelo foram discutidos na metodologia da pesquisa. No decorrer do texto além de apresentar os resultados do modelo construído, será realizado um cotejamento entre os resultados encontrados e os achados da literatura. O texto foi construído levando-se em consideração as três etapas da Metodologia Multicritério: (i) fase da estruturação; (ii) fase da avaliação; e (iii) fase de elaboração de recomendações.

\subsection{Fase da estruturação}

A primeira etapa da construção de conhecimento nos envolvidos no processo, que refletirá em um modelo de avaliação de desempenho econômico-financeiro para a empresa, foi realizada pela caracterização do contexto decisório. Buscou-se entender a insatisfação da Seprol Computadores e Sistemas em relação ao problema proposto. Além de entender a insatisfação, procurou-se conhecer o mercado em que a empresa está inserida, a estrutura administrativa e as políticas da empresa.

Desta forma, percebeu-se que a empresa enfrenta problemas relacionados com a altíssima concorrência, sendo que isso se reflete diretamente no processo de gestão, e assim deve buscar as mais variadas praticas de gerenciamento para apoiar os seus gestores. Sendo assim, a avaliação de desempenho surge como um instrumento a mais para melhorar o processo de gestão, em que se buscou construir um processo que permita elicitar os fatores considerados mais importantes relacionados diretamente ou indiretamente com o desempenho econômico-financeiro da empresa.

A empresa Seprol Computadores e Sistemas Ltda, têm como atividades a venda de computadores, acessórios, periféricos e softwares, e também presta assistência técnica especializada, representando diversas marcas importantes do mercado, tais como HP; Oracle; Microsoft, entre outras. A empresa atua a vários anos no mercado, sendo sua sede em São José - Santa Catarina e várias filiais pelo Estado.

$\mathrm{Na}$ sequência da etapa de contextualização se fez necessário identificar os atores que fazem parte deste contexto, pois são esses atores que direta ou indiretamente estarão influenciando a construção do modelo. Os decisores que participaram ativamente de todo o processo foram o diretor administrativofinanceiro e o gerente financeiro, sendo que o modelo foi construído por meio das percepções desses dois atores que são cobrados pelo desempenho econômico-financeiro da empresa. Os intervenientes foram os sócios da empresa, que não participaram diretamente do processo da construção do modelo, mas que influenciam os decisores. Os facilitadores foram os autores deste trabalho, que buscaram seguir a metodologia e integrar todas as atividades desenvolvidas. E como agidos, ou seja, os atores que poderiam ser considerados pelos decisores, mas que não tinham influência direta sobre eles, foram os demais colaboradores da empresa, os fornecedores, os clientes, as instituições financeiras, o governo e os sindicatos.

A última etapa da contextualização consistiu em elaborar em conjunto com os decisores um rótulo para o problema: avaliação de desempenho econômicofinanceiro da empresa Seprol Computadores e Sistemas Ltda.

A segunda etapa da estruturação realizou-se pelo levantamento por meio de entrevistas com os decisores dos Elementos Primários de Avaliação (EPAs). Nesta etapa solicitou-se que os decisores identificassem as preocupações que diretamente ou indiretamente influenciam no desempenho econômico-financeiro da Seprol Computadores e Sistemas Ltda. Deste processo surgiram 73 Elementos Primários de Avaliação (EPAs).

$\mathrm{Na}$ sequência buscou-se identificar conceitos orientados à ação. Cada EPA foi discutido com os decisores, com o objetivo de construir conhecimento sobre quais aspectos deveriam ser considerados em um modelo de avaliação de desempenho econômicofinanceiro. No Quadro 5 apresenta-se exemplos de EPAs, com os respectivos conceitos orientados a ação.

Neste momento do processo de construção do modelo de avaliação de desempenho, já é possível perceber que o conhecimento está sendo gerado nos decisores e também nos facilitadores, pois se inicia o entendimento de quais são os aspectos que direta e/ou indiretamente influenciam no desempenho econômicofinanceiro da empresa. A partir do momento que diversos stakeholders são envolvidos e de alguma forma direta ou indiretamente influenciam os decisores, 
percebe-se que os aspectos que estão sendo levados em consideração são particulares à empresa Seprol Computadores e Sistemas Ltda. e que, neste contexto, estão sendo considerados a missão da empresa, visão organizacional, a cultura da empresa, objetivos de curto e de longo prazo, conforme preconiza a literatura. (KAPLAN; NORTON, 2000; YEO, 2003; TUOMELA, 2005; JACOBSEN; HOFMANBANG; NORDBY, 2005; GARENGO; BIAZZO; BITITCI, 2005; MERCHANT, 2006; CHENHALL; LANGFIELD-SMITH, 2007; SKRINJAR; BOSILJVUKSIC; INDIHAR-STEMBERGER, 2008; PUNNIYAMOORTHY; MURALI, 2008).

Em seguida, identificados os EPAs e da construção dos conceitos orientados à ação, compreendeu-se melhor as preocupações do decisor em relação aos aspectos que direta ou indiretamente impactam no desempenho econômico-financeiro, sendo assim, foi possível elaborar as áreas de preocupação (clusters), conforme Figura 1.

No agrupamento dos conceitos, percebem-se três grandes dimensões que respondem pelo desempenho da Seprol: o primeiro, relacionado à gestão financeira; o segundo, relacionado aos recursos humanos da empresa; e o terceiro, relacionado ao mercado em que a empresa atua. Neste momento já é possível observar que não são apenas aspectos financeiros que respondem pelo desempenho econômico-financeiro, sendo que os aspectos intangíveis relacionados aos recursos humanos e de mercado merecem bastante

Quadro 5. Elementos primários de avaliação e conceitos orientados à ação.

\begin{tabular}{|lr|}
\hline \multicolumn{1}{|c|}{ EPAs } & Conceitos \\
\hline $\begin{array}{l}\text { 1 - Controle e nível de eficiência da } \\
\text { cobrança interna } \\
11 \text { - Captação de recursos }\end{array}$ & 1 - Garantir que os títulos sejam recebidos nas \\
& datas de vencimento ... prejudicar a liquidez. \\
7 - Distribuição dos resultados & 147 - Assegurar que sejam avaliadas as diversas possibilidades para \\
6 - Imagem & captação de recursos ... avaliação de poucas alternativas. \\
& 137 - Ter política de distribuição de resultados ... não distribuição. \\
14 - Logística & 135 - Assegurar uma boa imagem da empresa junto a sociedade e ao \\
& mercado ... falta de zelo com a imagem. \\
13 - Parcerias & 152 - Promover a satisfação do cliente por meio da entrega nos \\
& prazos estabelecidos ... ter clientes insatisfeitos. \\
& 151 - Promover a construção de parcerias estratégicas ... \\
\end{tabular}

Fonte: elaborado pelos autores.

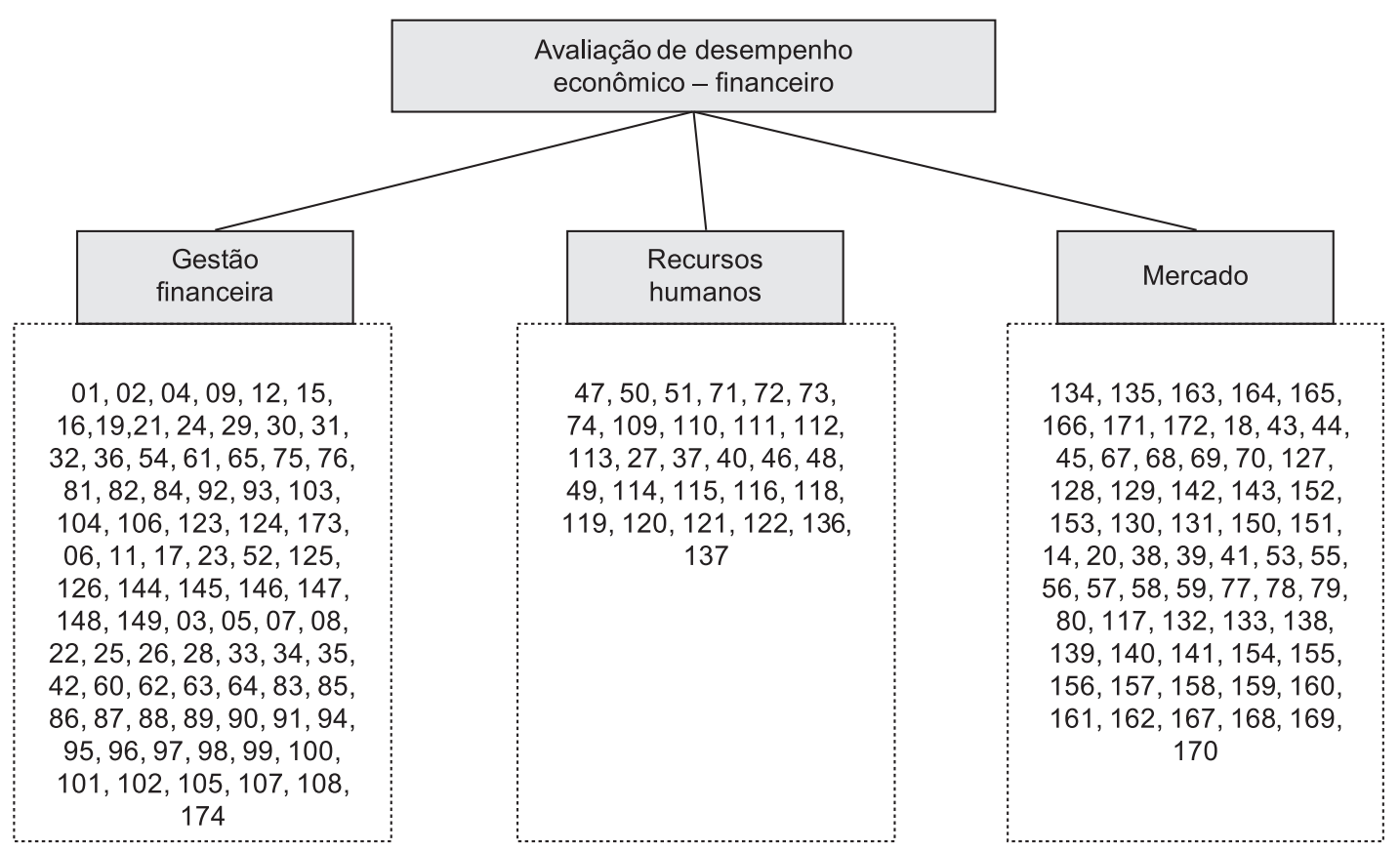

Figura 1. Conceitos agrupados por área de preocupação ou clusters. Fonte: elaborado pelos autores. 
atenção no contexto decisório. Os aspectos intangíveis são considerados na literatura como essências no atual contexto em que as empresas atuam, sendo que os aspectos somente financeiros já não respondem adequadamente às necessidades dos gestores. (HAN; HAN, 2004; GUTHRIE, 2001; KAPLAN; NORTON, 2000).

A próxima etapa da fase de estruturação consiste em elaborar os mapas de relações meios-fins e, em seguida, agrupá-los em clusters. Os mapas são elaborados tendo em sua base os conceitos meios, que também poderíamos chamar de preocupações operacionais, e, conforme vai se chegando ao topo do mapa, encontram-se os conceitos fins, que também poderíamos chamar de preocupações estratégicas. Neste trabalho, foram elaborados nove mapas de relações meios-fins, sendo que a importância da criação dos mapas é a continuação de construção do conhecimento nos decisores e para utilização na criação da estrutura hierárquica de valor. Apresenta-se na Figura 2 o mapa da dimensão "Gestão Financeira", área de resultados.

Nos mapas de relações meios-fins é possível identificar a relação de causa e efeito entre os objetivos operacionais e os objetivos estratégicos.
Segundo os trabalhos pesquisados que compõem a revisão da literatura, esses aspectos de ligar a estratégia ao operacional e entender as ligações existentes é de fundamental importância para o sucesso na implantação de um sistema de avaliação de desempenho (KAPLAN; NORTON, 2000; YEO, 2003; GARENGO; BIAZZO; BITITCI, 2005; PUNNIYAMOORTHY; MURALI, 2008)

A etapa seguinte do processo de estruturação consistiu na elaboração da estrutura hierárquica de valor, por meio da utilização dos mapas de relações meios-fins. Com a elaboração dos mapas, identificaram-se os pontos de vista fundamentais (PVFs), e o restante da estrutura hierárquica de valor, ou seja, os mapas ajudaram a fazer a transição do conhecimento gerado para uma estrutura, que representa em forma de árvore as dimensões que se pretende avaliar. Apresenta-se na Figura 3, a estrutura hierárquica de valor até o nível de pontos de vista fundamentais.

Verifica-se que a dimensão "Gestão Financeira" é respondida por três áreas: resultados, estrutura de capital e políticas. Percebem-se assim as grandes preocupações em relação à gestão financeira da empresa. A dimensão "Recursos Humanos" é

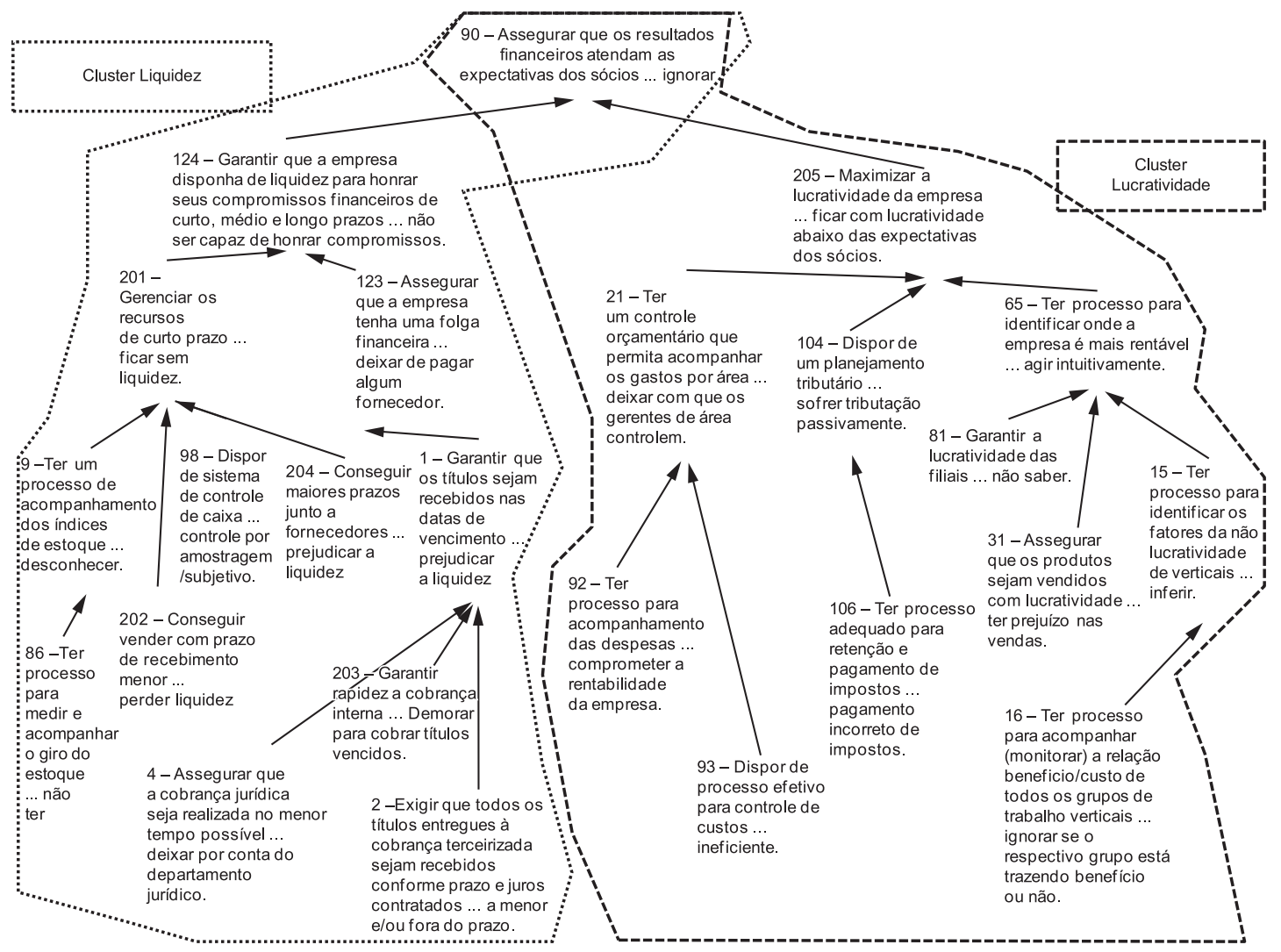

Figura 2. Mapa de relações meios-fins da área de resultados. Fonte: Elaborado pelos autores. 
respondida por duas áreas: motivação e produtividade. E a dimensão "Mercado" é respondida por quatro áreas: imagem, clientes, fornecedores e estratégia. Observa-se que compreende aspectos que direta ou indiretamente influenciam no desempenho econômico-financeiro da empresa, tendo uma visão clara e holística do que se pretende avaliar (KAPLAN; NORTON, 2000; GARENGO; BIAZZO; BITITCI, 2005).

Na última etapa da fase de estruturação, buscou-se elaborar os descritores para cada ponto de vista elementar e determinar os níveis de referência, conforme exemplificado na Figura 4.
Salienta-se que, na fase de estruturação, os descritores são ordinais, ou seja, o intervalo entre um nível e outro tem o mesmo nível de atratividade. Com essa etapa termina-se a fase de estruturação e parte-se para a fase de avaliação, que é apresentada a seguir.

\subsection{Fase da avaliação}

A primeira etapa da fase da avaliação consiste em transformar as escalas ordinais em escalas cardinais. Para exemplificar o processo, apresenta-se o

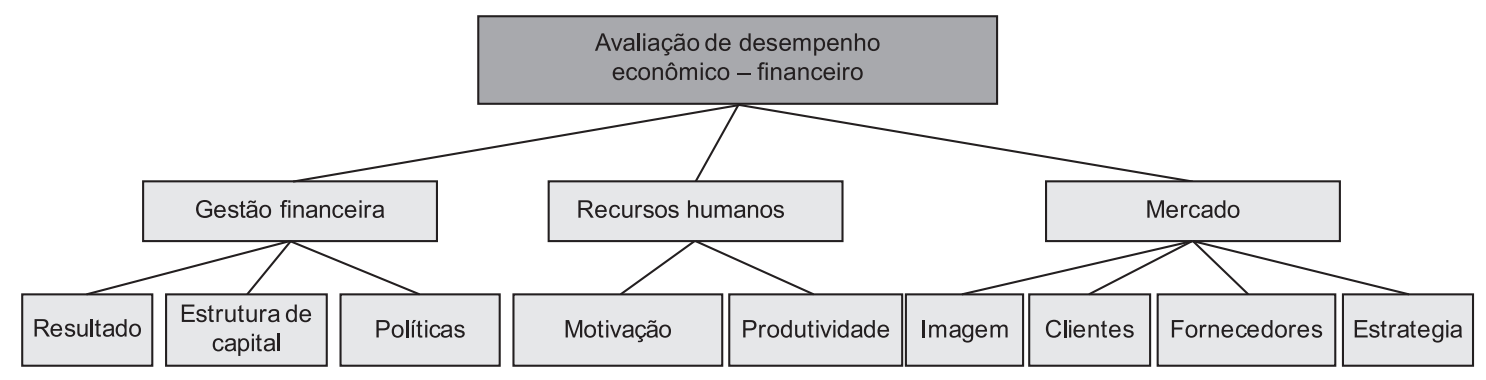

Figura 3. Estrutura hierárquica de valor até os pontos de vista fundamentais. Fonte: elaborado pelos autores.

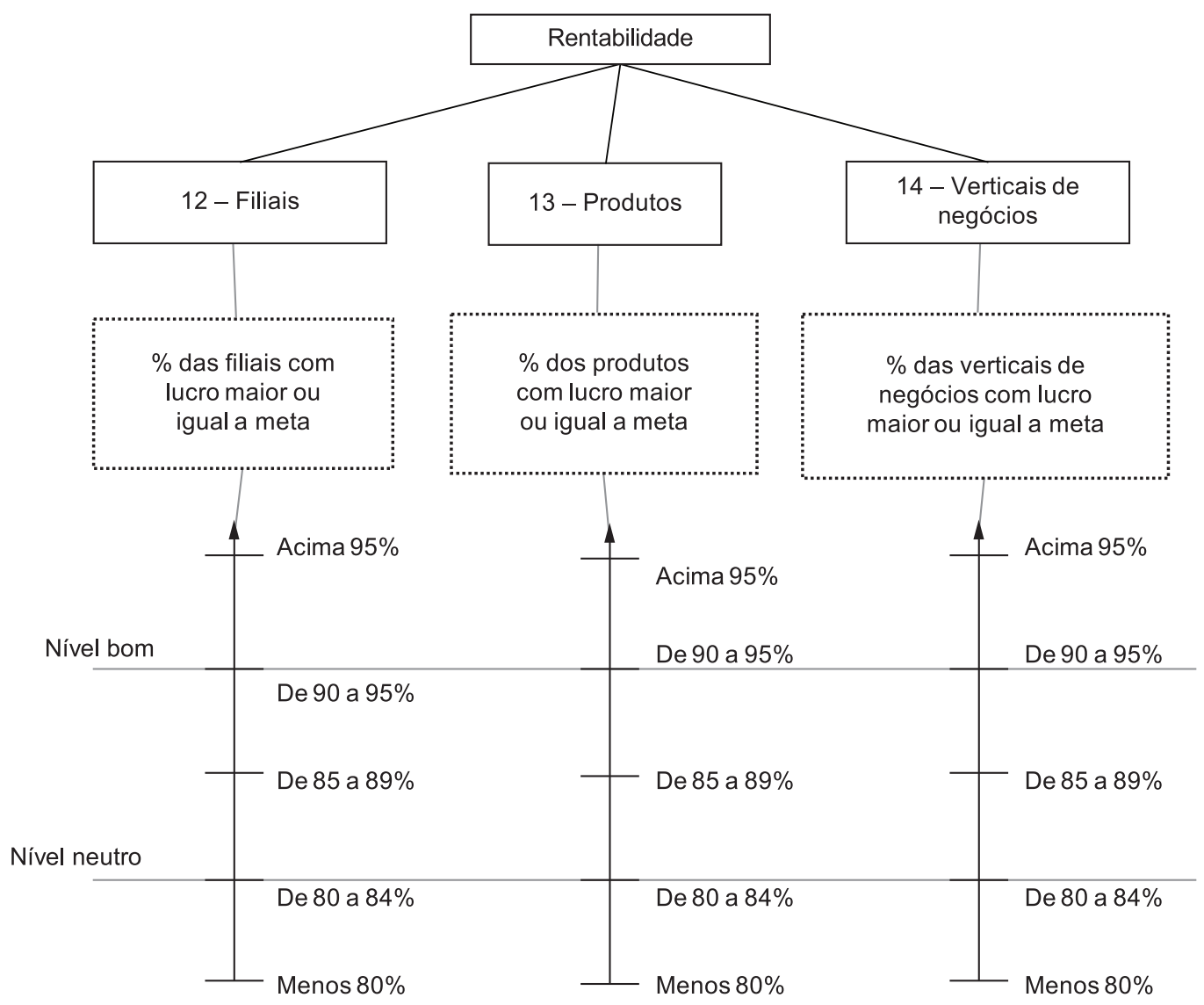

Figura 4. Elaboração dos descritores e determinação dos níveis de referências. Fonte: elaborado pelos autores. 
descritor "Clientes", que busca avaliar a porcentagem do faturamento vendido com prazo menor ou igual a 60 dias. O descritor "Clientes" está relacionado a giro/ liquidez/resultado/gestão financeira da avaliação de desempenho econômico-financeira. Com o auxílio do software Macbeth, solicita-se ao decisor que expresse a intensidade percebida entre passar de um nível a outro do descritor. Com esse julgamento, o software calcula a função de valor, conforme mostrado na Figura 5.

A etapa seguinte consistiu em calcular as taxas de substituição, as quais permitirão a agregação aditiva dos descritores, possibilitando a avaliação global de desempenho. Cabe lembrar que as taxas são calculadas levando em consideração os níveis bons e neutros. O primeiro passo para calcular as taxas de substituição consiste em hierarquizar os descritores por meio da matriz de Roberts (1979). Após essa etapa, utilizou-se, novamente, o software Macbecth para encontrar as taxas de substituição.

O resultado apontou que a dimensão "Gestão Financeira" irá responder por $50 \%$, a dimensão "Recursos Humanos" irá responder por $17 \%$, e a dimensão "Mercado" irá responder por $33 \%$ do modelo de avaliação de desempenho econômico-financeiro da Seprol. Com essas informações, é possível demonstrar o perfil de impacto, conforme Figura 6.

No caso do presente estudo, a avaliação do desempenho econômico-financeiro da empresa Seprol Computadores e Sistemas Ltda. foi de 42 pontos, o que se configura como um desempenho em nível de mercado; entretanto, aquém da expectativa do diretor administrativo-financeiro e do gerente financeiro.

A fase de avaliação permitiu gerar novos conhecimentos nos decisores, primeiramente, em relação à diferença percebida entre cada nível de impacto dos descritores; segundo, em relação à identificação das taxas de substituição, sendo que agora já é possível ter uma avaliação global de desempenho. Essa possibilidade contribui para identificar o impacto global da alteração em algum descritor pontual e, por fim, o decisor pode visualizar o perfil de impacto, possibilitando uma melhor visualização da situação em que se encontra o desempenho econômico-financeiro. Salienta-se que, nesse momento da construção do modelo, o decisor: (i) tem uma linguagem clara e holística de toda a organização (KAPLAN; NORTON, 2000; GARENGO; BIAZZO;

\begin{tabular}{|c|c|c|}
\hline Nível & Âncora & $\begin{array}{l}\text { Descrição: \% do faturamento com } \\
\text { prazo menor ou igual a } 60 \text { dias }\end{array}$ \\
\hline N5 & & De $90, . . \%$ a $100 \%$ \\
\hline N4 & Bom & De $80, . . \%$ a $90 \%$ \\
\hline N3 & & De $70, . . \%$ a $80 \%$ \\
\hline N2 & Neutro & De $50, . . \%$ a $70 \%$ \\
\hline N1 & & $50 \%$ ou menos \\
\hline
\end{tabular}

\begin{tabular}{|c|c|c|c|c|c|c|c|}
\hline \multicolumn{8}{|c|}{ Clientes } \\
\hline 圆 & N5 & N4 & N3 & N2 & N1 & Escala & extrema \\
\hline N5 & nula & fraca & moderada & forte & extrema & $\frac{a t u a l}{122.22}$ & mt. forte \\
\hline N4 & & nula & moderada & forte & extrema & 100.00 & forte \\
\hline N3 & & & nula & forte & extrema & 66.67 & moderada \\
\hline $\mathrm{N} 2$ & & & & nula & extrema & 0.00 & Hraca \\
\hline N1 & & & & & nula & -144.44 & nula \\
\hline \multicolumn{8}{|c|}{ lulgamentos consistentes } \\
\hline \multicolumn{8}{|c|}{ 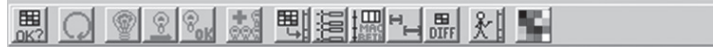 } \\
\hline
\end{tabular}

Figura 5. Descritor e escala cardinal (função de valor) do PVE-Clientes. Fonte: elaborado pelos autores.

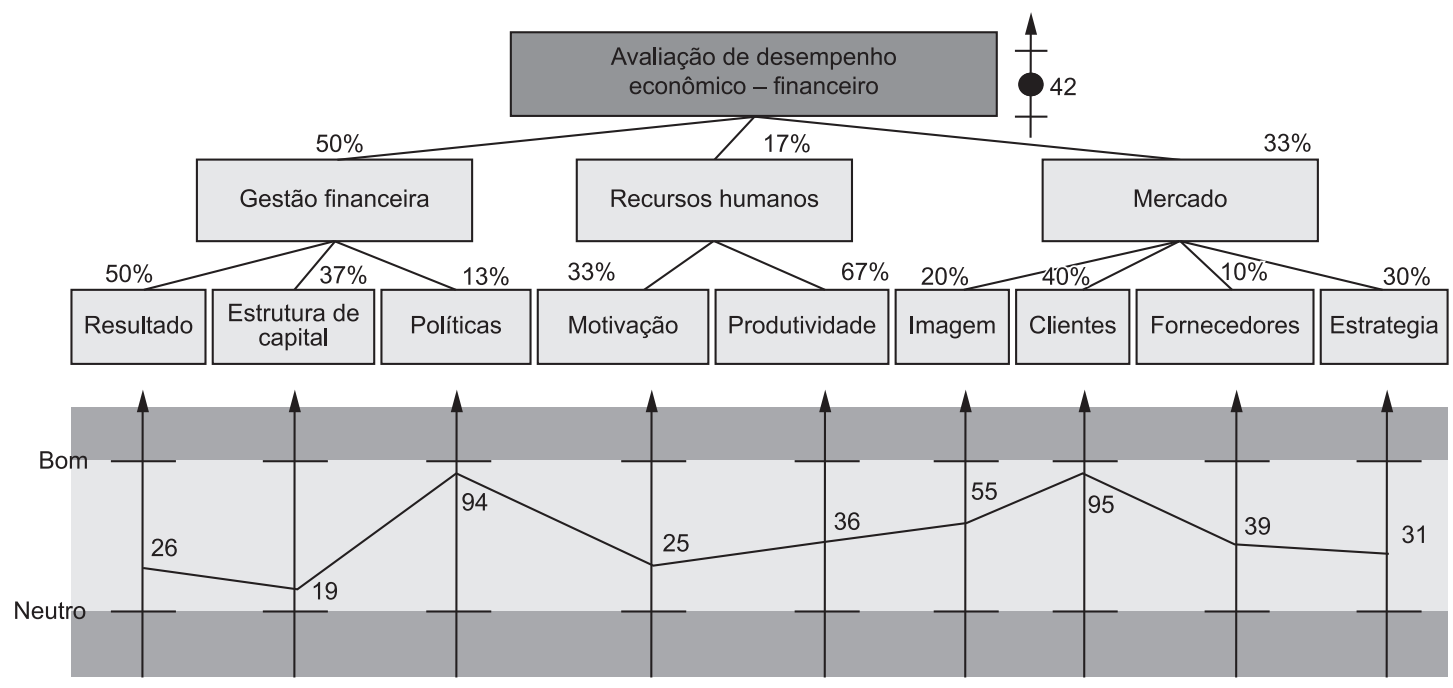

Figura 6. Perfil de desempenho do status quo e avaliação global do status quo. Fonte: elaborado pelos autores. 
BITITCI, 2005); (ii) consegue visualizar os objetivos estratégicos e operacionais que devem ser perseguidos; e, (iii) reconhece as relações de causa e efeito, sendo que isso possibilita a ligação entre as atividades operacionais e os objetivos estratégicos (KAPLAN; NORTON, 2000; YEO, 2003; GARENGO; BIAZZO; BITITCI, 2005; PUNNIYAMOORTHY; MURALI, 2008).

A importância da comunicação em todos os níveis da organização (YEO, 2003), para possibilitar que todos saibam quais os objetivos que devem ser perseguidos para atingir os objetivos estratégicos da organização (TUOMELA, 2005), fica bastante clara com o modelo proposto, pois se consegue visualizar nitidamente quais são as atividades que devem ser desenvolvidas nos níveis operacionais, gerenciais e estratégicos.

\subsection{Fase de elaboração de recomendações}

A fase de elaboração de recomendações consiste em utilizar todo o conhecimento gerado, que agora se reflete no modelo de avaliação do desempenho econômico-financeiro, no sentido de apoiar o decisor a encontrar estratégias para melhorar os descritores que são considerados comprometedores. Para ilustrar o processo de elaboração de recomendações, buscou-se demonstrar uma estratégia hipotética em relação aos aspectos financeiros da avaliação de desempenho econômico-financeiro. Por meio da visualização do desempenho pontual de alguns descritores da dimensão de gestão financeira, que estavam com desempenho comprometedor, foram identificadas ações que poderiam proporcionar a passagem do nível atual para um nível superior ao que se encontrava, conforme Tabela 1.

Com a implantação dessa estratégia, a empresa passaria de uma avaliação global de desempenho de 42 para 48 pontos, conforme pode ser observado na Figura 7.

Salienta-se que o impacto da área de resultados da dimensão gestão financeira, encontra-se em 26 pontos,

Tabela 1. Propostas de ações para os indicadores que apresentam desempenho comprometedor.

\begin{tabular}{lcc}
\hline \multicolumn{1}{c}{ Descritores/ações } & $\begin{array}{c}\text { Status } \\
\text { quo }\end{array}$ & $\begin{array}{c}\text { Após } \\
\text { implantação da } \\
\text { estratégia }\end{array}$ \\
\hline Reduzir o número de itens em estoque há mais de 60 dias & 70 itens & 50 itens \\
Aumentar o percentual do faturamento vendido com prazo menor ou igual a 30 dias & $65 \%$ & $70 \%$ \\
Aumentar o percentual de compras realizadas com prazo igual ou superior a 60 dias & $60 \%$ & $70 \%$ \\
Aumentar o percentual dos títulos com cobrança jurídica, recebidos em prazo & $55 \%$ & $70 \%$ \\
menor ou igual a 180 dias & $80 \%$ & $85 \%$ \\
Aumentar o percentual do orçamento de despesa realizado segundo as metas & \\
estabelecidas & &
\end{tabular}

Fonte: elaborado pelos autores.

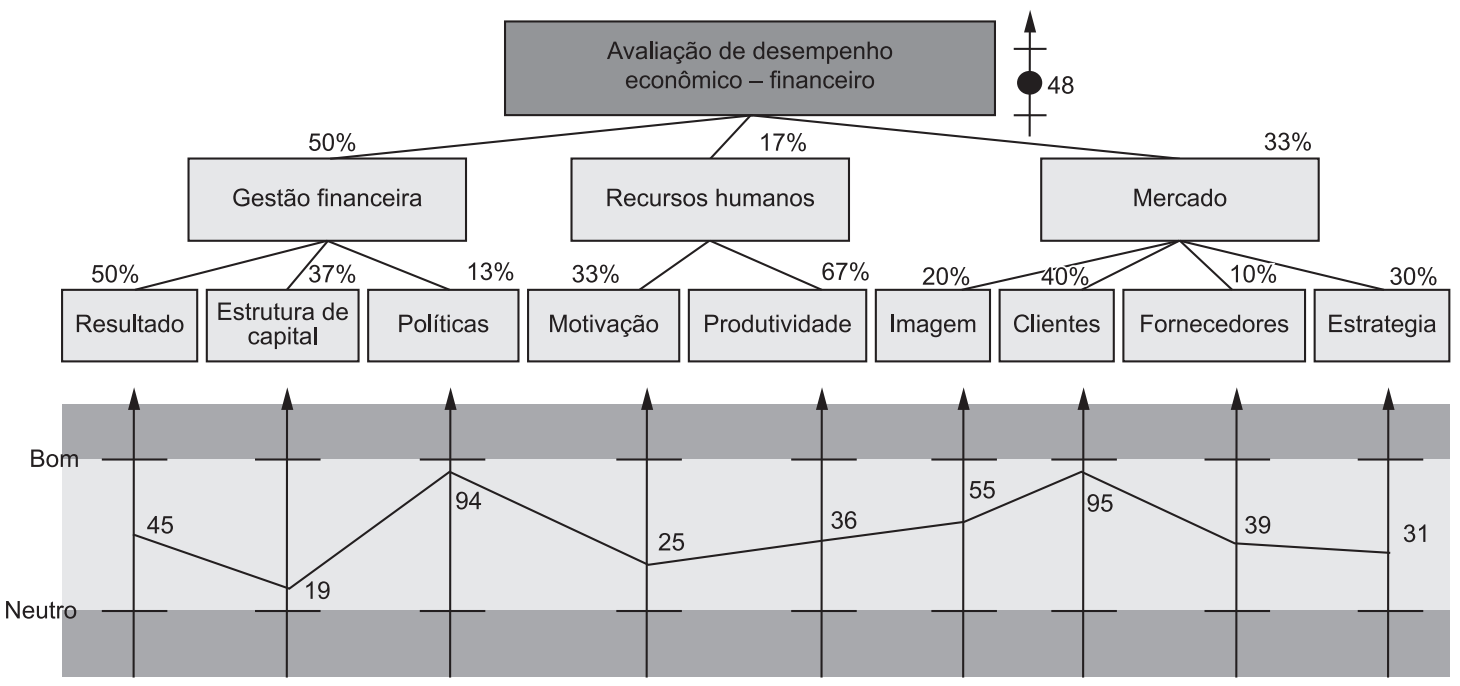

Figura 7. simulação de perfil de desempenho com a implantação da estratégia. Fonte: elaborado pelos autores. 
e passaria para 45 pontos, se as ações da estratégia forem implementadas com sucesso.

\section{Considerações finais}

O presente artigo teve o objetivo de construir um modelo de avaliação de desempenho econômicofinanceiro para a empresa Seprol Computadores e Sistemas Ltda., por meio da Metodologia MCDA-C. No sentido de conseguir alcançar o objetivo geral, fez-se necessário identificar os indicadores financeiros e não financeiros que respondem pelo desempenho econômico-financeiro da empresa; construir escalas ordinais e cardinais para os indicadores identificados; traçar o perfil de desempenho e avaliar o desempenho local e global; e, por fim, identificar os indicadores que necessitavam de ações de aperfeiçoamento.

Cabe salientar que as escalas ordinais são construídas na fase de estruturação do modelo. No entanto, na fase de avaliação transforma-se a escala ordinal em escala cardinal, conforme explicitado na seção 3.3. A metodologia MCDA-C utiliza-se da escala cardinal e das taxas de compensação para realizar a agregação aditiva dos descritores com o propósito de avaliar o desempenho dos pontos de vista fundamentais e do desempenho global.

Dessa forma, buscou-se, por meio de entrevistas com os decisores da empresa, identificar as preocupações que impactam no desempenho econômico-financeiro. Com esse processo, conseguiu-se identificar 73 elementos primários de avaliação, que, na sequência, foram transformados em conceitos orientados à ação, e esses conceitos foram agrupados em mapas de relações meios-fins com o objetivo de verificar a relação de causa e efeito de cada dimensão responsável pelo desempenho econômico-financeiro. Como resultado desse processo, identificaram-se indicadores que influenciam diretamente no desempenho econômicofinanceiro, conhecidos na literatura como indicadores financeiros, bem como indicadores que influenciam indiretamente no desempenho econômico-financeiro, que, na literatura, são chamados de indicadores não financeiros.

Adicionalmente a esse processo, os mapas de relações meios-fins foram transformados em uma estrutura hierárquica de valor, que permitiu uma melhor visualização dos objetivos que estão sendo avaliados, possibilitando a construção dos descritores. $\mathrm{Na}$ sequência, buscou-se transformar as escalas ordinais em escalas cardinais, ou seja, por meio da percepção dos decisores, foi possível identificar a diferença de atratividade percebida entre um nível do descritor em relação ao outro. Com os descritores construídos em uma escala cardinal e com a construção das taxas de substituição, foi possível traçar o perfil de desempenho econômico-financeiro para a empresa Seprol Computadores e Sistema Ltda., bem como identificar o desempenho global da empresa.
As informações geradas no decorrer da construção do modelo de avaliação permitiram gerar ações de aperfeiçoamento e criar estratégias e ações que pudessem fazer melhorar pontualmente o resultado de um descritor (avaliação local), bem como perceber, na avaliação global de desempenho, os impactos das ações realizadas nos descritores locais.

Dessa forma, o estudo contribuiu com uma proposta diferenciada para avaliar o desempenho econômico-financeiro, visto que conseguiu identificar os indicadores financeiros e não financeiros particulares da organização, mensurá-los, apresentar o perfil de desempenho e a avaliação global de desempenho e, por fim, apresentar um processo estruturado para gerar ações de aperfeiçoamento. Os resultados apresentados na pesquisa são compartilhados pela literatura sobre $\mathrm{ADO}$, principalmente no que diz respeito a levar em consideração as particularidades das organizações, que se traduzem na missão, visão, cultura, nas estratégias e nos objetivos específicos de cada empresa (KAPLAN; NORTON, 2000; YEO, 2003; TUOMELA, 2005; JACOBSEN; HOFMANBANG; NORDBY, 2005; GARENGO; BIAZZO; BITITCI, 2005; MERCHANT, 2006; CHENHALL; LANGFIELD-SMITH, 2007; SKRINJAR; BOSILJVUKSIC; INDIHAR-STEMBERGER，2008; PUNNIYAMOORTHY; MURALI, 2008).

Adicionalmente, outras preocupações são compartilhadas entre os autores deste trabalho e a literatura sobre o tema. Primeiro, a preocupação em ligar o estratégico ao operacional (KAPLAN; NORTON, 2000; YEO, 2003; PUNNIYAMOORTHY; MURALI, 2008): tal preocupação foi atendida nos "mapas de relações meios-fins" e na "estrutura hierárquica de valor". Segundo, a preocupação com o processo de comunicação, ou seja, fazer com que todos os níveis organizacionais saibam o que realmente se está perseguindo (KAPLAN; NORTON, 2000; TUOMELA, 2005). Finalmente, a preocupação em se ter uma linguagem clara e uma visão holística dos objetivos (KAPLAN; NORTON, 2000; GARENGO; BIAZZO; BITITCI, 2005), o que foi conseguido por meio da estrutura hierárquica de valor, do perfil de desempenho e da avaliação global de desempenho.

Dessa forma, argumenta-se que a Metodologia MCDA-C conseguiu cumprir o objetivo de construir um modelo de AD econômicofinanceiro específico para a organização e que atendeu completamente e simultaneamente às exigências de identificar os critérios a serem avaliados, mensurar adequadamente os critérios, integrar os critérios para se ter uma avaliação global e gerar ações de aperfeiçoamento, conforme preconizado pelo conceito de ADO adotado neste trabalho (IGARASHI et al., 2008).

Como limitações da pesquisa, apontam-se os seguintes aspectos: (i) o modelo tem legitimidade 
para a empresa estudada, portanto, a utilização do modelo aqui construído em outra empresa necessita de adequações; (ii) o modelo construído leva em consideração as percepções dos decisores, portanto, o modelo tem legitimidade para esses decisores no contexto em que estavam inseridos; (iii) as estratégias elaboradas na fase de recomendações foram simulações de cenários cujos resultados reais ainda não foram acompanhados; e, (iv) as simulações de estratégias foram feitas apenas para a dimensão "Gestão Financeira", não contemplando outras estratégias em outras dimensões.

Nesse sentido, sugere-se, para futuras pesquisas, que a proposta de $\mathrm{AD}$ econômico-financeiro sugerida por este estudo seja aplicada a outras empresas e com outros decisores, no sentido de consolidar a proposta como um caminho viável para avaliar o desempenho econômico-financeiro, considerando indicadores financeiros e não financeiros e as particularidades das organizações. Sugere-se, também, que outras pesquisas consigam acompanhar o resultado da implantação do modelo na empresa, bem como verificar a implantação da estratégia e os resultados alcançados. Por fim, propõe-se que sejam elaboradas novas estratégias para a empresa e que se verifique o impacto que as estratégias poderiam alcançar no modelo de avaliação de desempenho, expandindo as simulações para as demais dimensões.

\section{Referências}

BANA E COSTA, C. A. Três convicções fundamentais na prática do apoio à decisão. Pesquisa Operacional,v. 13, p. 1-12, 1993.

BANA E COSTA, C. A., SILVA, F. N. Concepção de uma "Boa" Alternativa de Ligação Ferroviária ao Porto de Lisboa: uma aplicação da metodologia multicritério de apoio à decisão e à negociação. Investigação Operacional, v. 14, p. 115-131, 1994.

BANA E COSTA, C.A., STEWART, T.J., VANSNICK, J.C. Multicriteria decision analysis: some toughts based on the tutorial and discussion sessions of the ESIGMA meetings.In: EUROPEAN CONFERENCE ON OPERATIONAL RESEARCH, 14., 1995, Jerusalém. Proceedings... Jerusalém: Hebrew University of Jerusalem, 1995. p. 261-272,

BANA E COSTA, C.A., VASNICK, J.C. Applications of the MACBETH Approach in the Framework of an Additive Aggregation Model. Journal of Multi-criteria DecisionAnalysis, v. 6, n. 2, p. 107-114, 1997. http://dx.doi.org/10.1002/ (SICI) 1099-1360(199703)6:2\%3C107::AIDMCDA147\%3E3.0.CO;2-1

BARZILAI, J. A New Methodology for Dealing with Conflicting Engineering Design Criteria. of the In: ANNUAL MEETING OF THE AMERICAN SOCIETY FOR ENGINEERING MANAGEMENT, 18., 1997, Virginia Beach. Proceedings... Virginia Beach, 1997. p. 73-79.
BORTOLUZZI, S. C.; ENSSLIN, S. R.; ENSSLIN, L. Avaliação de Desempenho dos Aspectos Tangíveis e Intangíveis da Área de Mercado: estudo de caso em uma média empresa industrial. RBGN Revista Brasileira de Gestão de Negócios, v. 12, n. 37, p. 425-446, 2010a.

BORTOLUZZI, S. C.; ENSSLIN, S. R.; ENSSLIN, L. Construção de um modelo de avaliação de desempenho para a gestão financeira de uma empresa de informática. CAP-Accounting and Management, v. 4, n. 4, p. 12-22, 2010b.

BORTOLUZZI, S. C.; ENSSLIN, S. R.; ENSSLIN, L. Avaliação de desempenho econômico-financeiro: uma proposta de integração de indicadores contábeis tradicionais por meio da metodologia multricritério de apoio a decisão construtivista (MCDA-C). Revista Alcance, v. 18, n. 2, p. 200-218, 2011.

BORTOLUZZI, S. C. et al. Práticas de Avaliação de Desempenho Organizacional em pequenas e médias empresas: investigação em uma empresa do porte médio do ramo moveleiro. Revista Produção Online, v. 10, n. 3, p. 551-576, 2010.

CARPES, M. M. M.; ENSSLIN, L.; ENSSLIN, S.R. Avaliação do desempenho das práticas de responsabilidade social na gestão organizacional por meio da metodologia MCDA-Construtivista: uma abordagem aos modelos já existentes. Revista Alcance, v. 13, n. 1, p. 91-112, 2006.

CHENHALL, R. H.; LANGFIELD-SMITH, K. Multiple Perspectives of Performance Measures. European Management Journal, v. 25, n. 4, p. 266-282, 2007. http://dx.doi.org/10.1016/j.emj.2007.06.001

EDEN, C. Cognitive mapping. European Journal of Operational Research, v. 36, p. 1-13, 1988. http:// dx.doi.org/10.1016/0377-2217(88)90002-1

ENSSLIN, L. et al. Avaliação do Desempenho de Empresas Terceirizadas com o Uso da Metodologia Multicritério de Apoio à Decisão- Construtivista. Revista Pesquisa Operacional, v. 30, n. 1, p. 125-152, 2010.

ENSSLIN, L.; MONTIBELLER, G. N.; NORONHA, S. M. Apoio à Decisão: Metodologias para Estruturação de Problemas e Avaliação Multicritério de Alternativas. Ed. Insular, 2001.

ENSSLIN, S. R.; LIMA, M. V. A. Apoio à tomada de decisão estratégica: uma proposta metodológica construtivista. In: ANGELONI, T.;MUSSI, C. C. (Orgs.). Estratégias Formulação, Implementação e Avaliação: O desafio das organizações contemporâneas. São Paulo: Saraiva, 2008.

GARENGO, P.; BIAZZO, S.; BITITCI, U. S. Performance measurement systems in SMEs: A review for a research agenda. International Journal of Management Reviews, v. 7, n. 1, p. 25-47, 2005. http://dx.doi. org/10.1111/j.1468-2370.2005.00105.x

GIL, A. C. Como elaborar projetos de pesquisa. 3. ed. São Paulo: Atlas, 1999.

GUTHRIE, J. The management, measurement and the reporting of intellectual capital. Journal of Intellectual Capital, v. 2, n. 1, p. 27 - 41, 2001. http://dx.doi. org/10.1108/14691930110380473

HAN, D.; HAN, I. Prioritization and selection of intellectual capital measurement indicators using analytic hierarchy process for the mobile telecommunications 
industry. Expert Systems with Applications,v. 26, n. 4, p. 519-527,2004. http://dx.doi.org/10.1016/j. eswa.2003.10.010

IGARASHI, D. C. C. et al. A qualidade do ensino sob o viés da avaliação de um programa de pós-graduação em contabilidade: proposta de estruturação de um modelo híbrido. RAUSP - Revista de Administração da Universidade de São Paulo, v. 43, n. 2, p. 117-137, 2008.

JACOBSEN, K.; HOFMAN-BANG, P.; NORDBY JUNIOR, R. The IC Rating? model by Intellectual Capital Sweden. Journal of Intellectual Capital,v. 6, n. 4, p. 570-587, 2005. http://dx.doi. org/10.1108/14691930510628834

KAPLAN, R.; NORTON, D. Using the Balanced Scorecard as a strategic management system. Harvard Business Review, p. 75-85, 1996.

KAPLAN, R.; NORTON, D. The Balanced Scorecard: the measures that drive performance. Harvard Business Review, p. 71-79, 1992.

KAPLAN, R. S.; NORTON, D. P. Having trouble with your strategy? Then map it. Harvard Business Review, v. 78, n. 5, p. 167-176, 2000. PMid:11143152.

KAPLAN, R. S.; NORTON, D. P. Measuring the Strategic Readiness of Intangible Assets. Harvard Business Review, v. 82, n. 2, p. 52-63, 2004. PMid:14971269.

KEENEY, R. L. Value Focused-Thinking: A Path to Creative Decision-making.Cambridge: Harvard Univ. Press, 1992.

LACERDA, R. T. O.; ENSSLIN, L.; ENSSLIN, S. R. A performance measurement framework in portfolio management: a constructivist case. Management Decision, v. 49, n. 4, p. 648-668, 2011a. http://dx.doi. org/10.1108/00251741111126530

LACERDA, R. T. O.; ENSSLIN, L.; ENSSLIN, S. R. A performance measurement view of IT project management. The International Journal of Productivity and Performance Management, v. 60, p. 132-151, 2011 b. http://dx.doi.org/10.1108/17410401111101476

LANDRY, M. A note on the concept of problem. Organization Studies, v.16, p. 315-343, 1995. http:// dx.doi.org/10.1177/017084069501600206

MERCHANT, K. A. Measuring general managers' performances: Market, accounting and combinationof-measures systems. Accounting, Auditing and
Accountability Journal, v. 19, n. 6, p. 893-917, 2006. http://dx.doi.org/10.1108/09513570610709917

PUNNIYAMOORTHY, M.; MURALI, R. Balanced score for the balanced scorecard: a benchmarking tool. Benchmarking: An International Journal, v. 15, n. 4, p. 420-443, 2008 .

RICHARDSON, R. J. Pesquisa Social: Métodos e Técnicas. 3. ed. São Paulo: Atlas, 1999.

ROBERTS, F. S. Measurement Theory. In: ROTA, G. C. (Ed.).Encyclopedia of mathematics and its applications. London: Addison-Wesley Publishing Company, 1979. v. 7.

ROY, B. Decision science or decision-aid science? European Journal of Operational Research, v. 8 , n. 1, p. 184-203, 1993. http://dx.doi. org/10.1016/0377-2217(93)90312-B

ROY, B. Multicriteria Methodology for Decision Aiding Dordrecht: Kluwer Academic Publishers, 1996.

SAATY, T. Multicriteria decision making. University of Pittsburg, 1988.

SKINNER, W. The productivity paradox. Management Review, n. 75, p. 41-45, 1986.

SKRINJAR, R.; BOSILJ-VUKSIC, V.; INDIHARSTEMBERGER, M. The impact of business process orientation on financial and non-financial performance. Business Process Management Journal,v. 14, n. 5, p. 738-754, 2008. http://dx.doi. org/10.1108/14637150810903084

TASCA, J. E. et al. An approach for selecting a theoretical framework for the evaluation of training programs. Journal of European Industrial Training, v. 34, n. 7,p. 631-655, 2010. http://dx.doi. org/10.1108/03090591011070761

TUOMELA, T. S. The interplay of different levers of control: A case study of introducing a new performance measurement system. Management Accounting Research, v. 16, n. 3, p. 293-320, 2005. http://dx.doi. org/10.1016/j.mar.2005.06.003

YEO, R. The tangibles and intangibles of organisational performance. Team Performance Management, v. 9, n. 7-8, p. 199-204, 2003.

YIN, R. K. Estudo de Caso: planejamento e métodos. 3. ed. Porto Alegre: Bookman, 2005. 